Hopman, P., Heins, M.J., Korevaar, J.C., Rijken, M., Schellevis, F.G. Health care utilization of patients with multiple chronic diseases in the Netherlands: differences and underlying factors.

\begin{tabular}{|l|l|}
$\begin{array}{l}\text { Postprint } \\
\text { Version }\end{array}$ & 1.0 \\
\hline Journal website & http://www.ejinme.com/article/S0953-6205(16)30288-6/abstract \\
\hline Pubmed link & $\underline{\text { https://www.ncbi.nlm.nih.gov/pubmed/27640914 }}$ \\
\hline DOI & $10.1016 /$ j.ejim.2016.08.025 \\
\hline
\end{tabular}

This is a NIVEL certified Post Print, more info at http://www.nivel.eu

\title{
Health care utilization of patients with multiple chronic diseases in the Netherlands: Differences and underlying factors $i s$
}

\author{
PETRA HOPMAN ${ }^{\mathrm{A}}$, MARIANNE J. HeINS ${ }^{\mathrm{A}}$, JOKE C. KOREVAAR ${ }^{\mathrm{A}}$, MiEKe RIJKeN ${ }^{\mathrm{A}}$, FranÇOIS G. \\ SCHELLEVIS ${ }^{\mathrm{A}, \mathrm{B}, \text {, }}$ \\ ${ }^{a}$ NIVEL, Utrecht, The Netherlands \\ ${ }^{\mathrm{b}}$ Department of General Practice \& Elderly Care Medicine, EMGO Institute for Health and \\ Care Research, VU University Medical Centre, Amsterdam, The Netherlands
}

\section{ABSTRACT}

Purpose

To examine health care utilization of people with multiple chronic diseases in The Netherlands compared to people with a single chronic disease, and to identify subgroups of multimorbid patients according to health care utilization. Methods

All patients diagnosed with one or more chronic diseases in 2008-2009 $(\mathrm{N}=54,051)$ were selected from the nationwide NIVEL Primary Care Database, and data on their GP contacts and medication in 2010 were retrieved. Data on hospital admissions, household size and income were added. Chi-square-tests and multivariate regression analyses were performed to analyze differences between multimorbid patients and patients with a single chronic disease, and between subgroups of multimorbid patients derived from cluster analysis.

Results

Multimorbid patients (37\% of all patients) had more GP contacts, prescribed medications, and hospital admissions (all $p<.0001$ ) than patients with a single chronic disease. The largest cluster of multimorbid patients $(57 \%)$ had a relatively low level of health care utilization, a smaller cluster (36\%) had higher levels of health care utilization, and $7.6 \%$ of patients were heavy health care users ( $p<.0001$ for all variables). The latter were older, more often female, had a lower income, lived in a smaller household, had more chronic diseases, and more often had specific chronic diseases such as COPD, diabetes and heart failure.

Conclusions 
Hopman, P., Heins, M.J., Korevaar, J.C., Rijken, M., Schellevis, F.G. Health care utilization of patients with multiple chronic diseases in the Netherlands: differences and underlying factors. European Journal of Internal Medicine: 2016, 35(11), 44-50

The majority of multimorbid patients have only slightly higher health care utilization than patients with a single chronic disease. Extensive health care utilization among multimorbid patients seems to be related to patient characteristics as well as chronic disease numbers and patterns.

\section{INTRODUCTION}

Due to rapid aging and greater longevity of the population as well as increasing improvement of medical care, a growing number of people are living with a chronic disease [1]. Thirty percent of the population of the European Union (EU) is living with a chronic disease [2] and this percentage is expected to further increase in the next decades [3]. An increasing proportion of people with a chronic illness suffers from multimorbidity [4] and [5], which refers to the co-occurrence of multiple chronic diseases within a person [6] and [7]. The total number of people with multimorbidity in the EU is conservatively estimated at about 50 million [8].

Especially among older people the prevalence of multimorbidity is very high: among people over age 65 the proportion of individuals with multiple chronic diseases is estimated at about 65\%; among people over age 85 at about $85 \%$ [9] and [10].

Multimorbidity is associated with a poor functional status [11], poor quality of life [12], [13] and [14], more psychological distress [15], and mortality [16].

Multimorbidity may also be associated with higher levels of health care utilization, not only in comparison to people without a chronic disease but also to people with a single chronic disease [12]. Since health care systems are under pressure (not the least as a result of the growing number of people with [multiple] chronic diseases and the consequential burden on financial and human resources), the innovation of chronic illness care/management in order to provide good quality care (with limited resources) is urgently needed. Integrated care has the potential to meet the complex needs of people with multiple chronic conditions, while making more efficient use of resources [8]. To allocate resources as efficiently as possible, it may be helpful to identify the subgroup of multimorbid patients who are most care and support demanding. This would allow the health system to better respond to the needs of specific subgroups of multimorbid patients, for instance by developing targeted integrated care programs [17], [18] and [19].

It is, however, hard to identify multimorbid patients with extensive or complex health care needs merely based on particular combinations of chronic conditions. Sinnige and colleagues, who studied multimorbidity patterns in an elderly general practice population, argued that multimorbidity is "far more complicated than merely the presence of two co-occurring diseases within a person", and that the knowledge on comprehensive disease patterns should be taken into account when providing care for multimorbid patients. [20] Moreover, apart from illness-related factors, needs might also relate to individual patient characteristics such as socio-demographic and social characteristics (e.g. age, gender, education level, and living situation). The identification of profiles of groups of multimorbid patients with extensive health care needs will allow the health and social care system to better respond to their needs, for example by developing and implementing integrated care programs, or providing case management [8], [17], [18] and [19]. 
Hopman, P., Heins, M.J., Korevaar, J.C., Rijken, M., Schellevis, F.G. Health care utilization of patients with multiple chronic diseases in the Netherlands: differences and underlying factors. European Journal of Internal Medicine: 2016, 35(11), 44-50

The aim of this study was therefore to gain more insight into the (differences in) health care utilization of multimorbid patients. More specifically, the current research addresses the following research questions:

1. How does health care utilization of patients with multimorbidity differ from health care utilization of patients with a single chronic disease?

2. Which subgroups of multimorbid patients can be distinguished on the basis of their health care utilization?

3. Which patient and illness characteristics are associated with these subgroups of multimorbid patients?

\section{METHODS}

To answer these research questions we combined data on morbidity, health care utilization and personal characteristics of three databases.

\subsection{Databases}

\subsubsection{NIVEL Primary Care Database}

NIVEL Primary Care Database (formerly known as LINH) is a nationally representative database that holds longitudinal data derived from patients' electronic medical records (EMR) on consultations, morbidity, drug prescriptions, and referrals. [21] In 2010, about 130 Dutch general practices provided data [22]. General practitioners (GPs) code diagnoses using the International Classification of Primary Care (ICPC-1) [23].

\subsubsection{Dutch Hospital Data}

The Dutch Hospital Data (DHD) database contains information on all day care and inpatient admissions for approximately $88 \%$ of all hospitals in the Netherlands [24].

\subsubsection{Integrated Income Data - Households database}

The Integrated Income Data - Households database, from Statistics Netherlands, contains information on the disposable income and size of each household in the Netherlands [25]. This is mainly derived from tax administration.

\subsubsection{Linkage}

Data from the three databases were linked using postal code, gender, and date of birth. Linkage was performed by a Trusted Third Party (TTP) and researchers only had access to anonymized data. To perform this linkage, patients had to be uniquely identifiable, i.e. no other persons with the same combination of date of birth, gender, and postal code should be present. 
Hopman, P., Heins, M.J., Korevaar, J.C., Rijken, M., Schellevis, F.G. Health care utilization of patients with multiple chronic diseases in the Netherlands: differences and underlying factors. European Journal of Internal Medicine: 2016, 35(11), 44-50

\subsection{Study population}

From the NIVEL Primary Care Database, we selected patients aged 18 years and older who had at least one chronic disease according to their medical record. For this study, we used a list of 29 chronic diseases which had been selected for previous studies based on their high prevalence among the general Dutch population and their chronic and severe character [26] and [20] (see Appendix A). In the Netherlands, all non-institutionalized inhabitants are listed in a general practice, and all consultations with the GP are fully reimbursed by the mandatory health insurance. The GP is usually the first professional to be consulted for health problems, and acts as a gatekeeper to secondary care. As medical records in primary care practice are generally complete and representative of the entire population, these are especially suitable for estimating prevalence of chronic diseases.

To be included in this study, patients were required to be registered in the same practice during the full period 2008-2010. By using a minimal period of three years, diagnoses were determined more accurately, as for some chronic diseases patients do not necessarily visit their GP each year. The data quality was assessed at practice level. Patient data were only used from practices who met the quality criteria for recording morbidity data in 2008-2009 and for health care utilization data in 2010.

This study was executed according to the precepts of the Dutch legislation on privacy and the regulations of the Dutch Data Protection Authority. According to Dutch legislation, studies using this kind of observational data do not require medical ethical approval, or informed consent.

\subsection{Patient and illness-related characteristics}

Data about age, gender, number and type(s) of chronic diseases were derived from NIVEL Primary Care Database. Disposable income (in Euros, over the year 2010) and household size (in the year 2010) were derived from the Integrated Income Data - Households database. Disposable income is defined as gross income minus: interhousehold transfers paid, income insurance premiums, health insurance premiums, and capital income and gain taxes.

\subsection{Health care utilization}

\subsubsection{GP care utilization}

Data on the number of GP contacts in the year 2010 were derived from NIVEL Primary Care Database. Based on this number, we calculated an additional variable 'having had $\geq 1$ GP contact in 2010' (yes $=1$, no $=0$ ).

\subsubsection{Medication use}

Data on the number of prescribed medications in the year 2010 were derived from NIVEL Primary Care Database. The number of different medications was calculated at ATC3-level. Based on this number, we calculated an additional variable 
Hopman, P., Heins, M.J., Korevaar, J.C., Rijken, M., Schellevis, F.G. Health care utilization of patients with multiple chronic diseases in the Netherlands: differences and underlying factors. European Journal of Internal Medicine: 2016, 35(11), 44-50

'polypharmacy' (yes $=1$, no $=0$ ), which reflects whether patients were prescribed ten or more different types of medications in 2010 on ATC3-level.

\subsubsection{Hospital admission}

Data on the number of day care and inpatient admissions to Dutch hospitals in 2010 were derived from the Dutch Hospital Data (DHD) database. Based on these numbers, we calculated two additional variables: 'with $\geq 1$ day care admission (yes $=1$, no $=0$ ) to the hospital in 2010' and 'with $\geq 1$ one inpatient admission $($ yes $=1$, no $=0)$ to the hospital in 2010' (both: yes $=1$, no $=0$ ). Outpatient hospital care was not included in the analyses.

\subsection{Data analysis}

First, we compared patients diagnosed with a single chronic disease with those diagnosed with more than one chronic disease (multimorbidity) on the aforementioned patient and illness-related characteristics and health care utilization (research question 1). Differences between the two groups were tested with logistic regression analysis and Chi-square-tests, except for the number of GP contacts, which was tested using multivariate negative binomial regression analyses [27]. We chose this type of regression analysis since the number of GP consultations is a rate and this type of regression analysis predicts the rate of an event.

Next, to investigate differences in health care utilization among multimorbid patients (research question 2), cluster analysis was conducted [28]. We performed both hierarchical cluster analysis (complete linkage) and kmeans clustering. We first tested the stability of the analyses by performing several analyses with a random $95 \%$ sample. The Calinsky-Harabasz ratio was used as a stopping rule to determine the number of clusters. Based on the results we determined which type best suited the data. Cluster analysis was performed with the following clustering variables: number of GP contacts in 2010, number of prescribed medications in 2010, having had at least one day care admission to a hospital in 2010, and having had at least one inpatient admission to a hospital in 2010.

Finally, we performed a series of regression analyses (multiple, logistic) and Chisquare-tests in which we tested for differences in patient and illness characteristics between the groups identified by the cluster analysis (research question 3). Groups were added as dummy variables and dependent variables were prevalence of each of the listed chronic diseases, gender, age, household size, and income.

\section{RESULTS}

\subsection{Patients with multimorbidity versus a single chronic disease compared}

\subsubsection{Patient characteristics and morbidity}

The total sample consisted of 54,051 patients with one or more medically diagnosed chronic diseases. Sixty-three percent of them $(N=33,844)$ had a single chronic disease, and $37 \%(N=20,167)$ were multimorbid. Compared to the subgroup of 
Hopman, P., Heins, M.J., Korevaar, J.C., Rijken, M., Schellevis, F.G. Health care utilization of patients with multiple chronic diseases in the Netherlands: differences and underlying factors. European Journal of Internal Medicine: 2016, 35(11), 44-50

patients with a single chronic disease (55.1\%), the subgroup of multimorbid patients consisted of a somewhat higher proportion of women $\left(58.2 \% ; \chi^{2}[1]=48.51\right.$, $p<.0001)$. Also, multimorbid patients were older $(M=65.0$ years, $S D=14.7)$ than patients with a single chronic disease $\left(M=53.6\right.$ years, $S D=16.5 ; L R \chi^{2}$ $[1]=5299,80, p<.0001)$. The five most prevalent chronic diseases among the sample of multimorbid patients were hypertension (55.4\%), diabetes mellitus $(30.0 \%)$, coronary artery disease $(16.4 \%)$, chronic back/neck pain $(15.8 \%)$, and osteoarthritis (14.6\%). Among the group with a single chronic disease hypertension (26.1\%), asthma (9.9\%), chronic back/neck pain (9.2\%), diabetes mellitus $(8.6 \%)$, and depression (and psychosis; 6.9\%) were most prevalent. Appendix B provides a full overview.

Data on household size and income were available for 46,011 patients $(85 \%)$. Compared to patients with a single chronic disease $\left(M_{€}=36,442, S D_{€}=24,604\right)$, patients with multiple chronic diseases had on average a lower annual disposable income $\left(M_{\epsilon}=30,737, S D_{€}=19,316 ; F[1,46,009]=682.77, p<.0001\right)$. Also, multimorbid patients lived in a smaller household $(M=2.00, S D=1.01)$ than patients with a single chronic disease $(M=2.44, S D=1.24 ; F[1,46,009]=1508.31$, $p<.0001)$.

\subsubsection{Healthcare utilization}

\subsubsection{GP contacts}

As Table 1 shows, the proportion of patients with at least one GP visit in 2010 is higher among multimorbid patients than among patients with a single chronic disease $\left(\chi^{2}[1]=791.90, p<.0001\right)$. On average, multimorbid patients visited the GP more than eight times in 2010, which is more frequent than patients with a single chronic disease who visited the GP somewhat more than five times $\left(L R \chi^{2}[1]=3641.68\right.$, $p<.0001)$.

\subsubsection{Prescribed medications}

On average, multimorbid patients had a higher number of prescribed different medications $(M=7.07, S D=4.32)$ than patients with a single chronic disease $\left(M=3.90, S D=3.26 ; L R \chi^{2}[1]=7848.62, p<.0001\right)$. The proportion of patients with polypharmacy is higher among multimorbid patients $(24.95 \%)$ than among patients with a single chronic disease $\left(6.36 \% ; \chi^{2}[1]=3800, p<.0001\right)$.

\subsubsection{Hospital admissions}

The proportion of patients with at least one day care admission in 2010 is higher among multimorbid patients $(14.23 \%)$ than among patients with a single chronic disease $\left(8.78 \% ; \chi^{2}[1]=311.04, p<.0001\right)$. Also, a greater proportion of multimorbid patients $(15.82 \%)$ had at least one inpatient admission compared to patients with a single chronic disease $\left(8.75 ; \chi^{2}[1]=499.43, p<.0001\right)$. 
Hopman, P., Heins, M.J., Korevaar, J.C., Rijken, M., Schellevis, F.G. Health care utilization of patients with multiple chronic diseases in the Netherlands: differences and underlying factors. European Journal of Internal Medicine: 2016, 35(11), 44-50

\subsection{Subgroups of multimorbid patients on the basis of health care utilization}

Of the 20,167 multimorbid patients, data on health care use, hospitalizations, income, and household size were available for 16,482 patients (82\%). Kmeans clustering resulted in the most robust results. Cluster analysis revealed a three-cluster solution as the optimal number of clusters that could explain the profile structure of health care utilization of multimorbid patients (see Table 2).

\section{[TABLE 2]}

As shown in Table 2, Cluster 1 is the largest cluster $(n=9385 ; 57 \%)$, characterized by relatively low levels of health care utilization. Ninety percent of the patients in this cluster visited the GP at least once in 2010; the average number of visits was 3.8 $(S D=2.4)$. Patients in Cluster 1 were prescribed on average somewhat less than five different types of medications, and $5.5 \%$ of the patients had polypharmacy. With regard to hospital admissions, $10 \%$ had at least one day care admission and $9.2 \%$ had at least one inpatient admission in 2010.

Cluster 2 comprises a smaller though substantial number of patients $(n=5847 ; 36 \%)$, and is characterized by higher levels of health care utilization. All people in Cluster 2 visited the GP at least once in 2010, and the average number of visits was 11.8 $(S D=3.5)$. Patients in Cluster 2 were prescribed on average somewhat more than nine different types of medications, and $44.0 \%$ of the patients had polypharmacy. With regard to hospital admissions, $18.7 \%$ had at least one day care admission and $21.8 \%$ had at least one inpatient admission in 2010.

Cluster 3 comprises only $7.6 \%(n=1250)$ of the multimorbid patients, and is characterized by very high levels of health care utilization. All these people visited the GP at least once in 2010, and the average number of visits was $28.0(S D=9.6)$. Patients in Cluster 3 were prescribed on average more than thirteen different types of medications, and almost eight out of ten patients had polypharmacy. With regard to hospital admissions, more than a quarter of the patients in Cluster 3 had at least one day care admission and almost four out of ten had at least one inpatient admission in 2010. Clusters differed significantly $(p<.0001)$ on all health care utilization measures.

\subsection{Characteristics of subgroups of multimorbid patients}

\subsubsection{Patient characteristics}

As shown in Table 3, the cluster associated with relatively low levels of health care utilization (Cluster 1) contains somewhat more women than men (54\% vs. $46 \%)$, and the average age is about 63 years. The yearly disposable income of these people was 33,306 Euros and they lived in a household of 2.1 persons on average. The cluster associated with higher (but not the highest) levels of health care utilization (Cluster 2 ) contains more women than men $(62 \%$ vs. $38 \%)$ and the average age is 68 years. The yearly disposable income of people in Cluster 2 was 28,930 Euros, and they lived in a household of 1.9 persons on average. The cluster associated with the 
Hopman, P., Heins, M.J., Korevaar, J.C., Rijken, M., Schellevis, F.G. Health care utilization of patients with multiple chronic diseases in the Netherlands: differences and underlying factors. European Journal of Internal Medicine: 2016, 35(11), 44-50

highest levels of health care utilization (Cluster 3) contains more than twice as many women as men ( $70 \%$ vs. $30 \%)$ and the average age is almost 72 years, which is almost ten years older than people in Cluster 1 . The yearly disposable income of people in Cluster 3 was 25,030 Euros, which is only $75 \%$ of the yearly disposable income of people in Cluster 1. People in Cluster 3 lived in a household of 1.7 persons on average. Clusters differed significantly $(p<.0001)$ on all patient characteristics.

\section{[TABLE 3]}

\subsubsection{Clinical characteristics}

People in the cluster that is associated with relatively low levels of health care utilization (Cluster 1) had $2.4(S D=0.7)$ chronic diseases on average. The five most prevalent chronic diseases among patients in Cluster1 were hypertension (54.8\%), diabetes mellitus $(26.2 \%)$, chronic back/neck pain (16.3\%), coronary artery disease $(14.2 \%)$, and osteoarthritis (13.9\%). People in Cluster 2 had $2.7(S D=1.0)$ chronic diseases on average, and the five most prevalent chronic diseases among them were hypertension $(60.1 \%)$, diabetes mellitus $(33.4 \%)$, coronary artery disease $(19.6 \%)$, COPD (16.6\%), and osteoarthritis (16.2\%). People in the cluster that is associated with the highest levels of health care utilization (Cluster 3) had $3.1(S D=1.2)$ chronic diseases on average. The five most prevalent chronic diseases among these patients were hypertension (55.9\%), diabetes mellitus (43.5\%), COPD (23.9\%), coronary artery disease $(20.8 \%)$, and osteoarthritis $(17.5 \%)$.

On average, people in clusters that are associated with higher health care utilization had more chronic diseases $\left(L R \chi^{2}[2]=311.28, p<.0001\right)$. When looking at individual chronic diseases, for 13 out of 17 diseases the presence varied across the three clusters (see Table 3 and Appendix C). Of these 13 chronic diseases, 11 were more common in the cluster(s) with the highest health care utilization. Especially heart failure, COPD, anxiety disorder, and diabetes mellitus were more common in the cluster with the highest health care utilization. Migraine, in contrast, was more common in the cluster with the lowest health care utilization. Anxiety disorder was (slightly) more common in the clusters with the highest and the lowest health care utilization, but less common in the middle cluster. The prevalence of asthma, depression, hearing disorder and chronic back or neck pain did not differ between the three clusters $\left(\chi^{2}\right.$ - and $p$-values in Table 3$)$.

\section{DISCUSSION}

Health care utilization is higher among multimorbid patients than among patients with a single chronic disease, but there is a large subgroup of multimorbid patients (about $60 \%$ ) in which healthcare utilization is only slightly higher compared to patients with a single chronic disease, suggesting that these people, with the right support, are fairly able to provide in their own care and manage their conditions. A smaller group (however more than one third of all multimorbid patients) utilizes health care services or medications considerably more often, suggesting that these people have greater difficulty in managing their conditions, and might therefore benefit from disease management provided by multidisciplinary teams of health care 
Hopman, P., Heins, M.J., Korevaar, J.C., Rijken, M., Schellevis, F.G. Health care utilization of patients with multiple chronic diseases in the Netherlands: differences and underlying factors. European Journal of Internal Medicine: 2016, 35(11), 44-50

providers. A relatively small subgroup of multimorbid patients $(7.6 \%)$ makes extensive use of healthcare, suggesting that their care is disproportionally complex and difficult to manage for themselves as well as for the health care system. These people might therefore benefit most from integrated care and case management.

Multimorbid patients with high health care utilization are thus most likely to benefit from integrated care. In order to optimally meet their comprehensive needs, it is important to identify the patients with more complex needs. With respect to patientrelated characteristics, and in line with previous research [29] and [30] our findings show that these patients are older (i.e. patients with the most complex needs were over 70 years on average), more often female (i.e. seven out of ten patients with extensive health care use), have a lower disposable income (on average, the disposable income of the most complex patients is only $75 \%$ of that of patients with a single chronic disease), and they have a smaller household size, which implies that they are relatively often living alone. Interestingly, a recent Canadian study did not find a relationship between income and primary health care use of older multimorbid patients, which they attributed to the relatively small variation in SES and universal access to health care [31].

With respect to clinical or illness characteristics it is also possible to draw a profile of multimorbid patients with more complex health care needs. Not only do they suffer from more chronic diseases than multimorbid people with a lower health care utilization, they also differ considerably with respect to the types of chronic diseases they suffer from. Especially heart failure, COPD, and diabetes mellitus are relatively common among multimorbid patients with a high use of primary and hospital care. Heart failure, COPD and diabetes have also proven to be strong predictors in several risk stratification models predicting negative health outcomes [32] and high health care costs [33], and synergistic negative effects on physical functioning and high health care costs have been found for disease pairs consisting of chronic respiratory disease, diabetes and/or cardiovascular disease [12] and [34].

The prevalence of anxiety disorder was remarkable as well since this disease was, in a relative way, especially prevalent among multimorbid patients with an extensive health care use and somewhat more prevalent (than could be expected based on the distribution of patients among the three clusters) among multimorbid patients with a low health care use, whereas the prevalence of anxiety disorder was relatively low among patients with a heightened (but not the highest) health care use. Possibly, anxiety symptoms or complaints arise from the burden of suffering from multiple diseases and the difficulty (or inability) to cope with and control these diseases. However, no research is known examining the relation of (somatic) multimorbidity and anxiety disorder. Further research might provide more insight into this matter.

\subsection{Strengths and limitations}

A strength of our study is that it was not susceptible to the potential recruitment bias often associated with studies focusing on patients recruited through hospitals or clinics. Data (of a large sample) of patients with one or more chronic disease were available, and selection bias was minimal since almost all Dutch inhabitants are 
Hopman, P., Heins, M.J., Korevaar, J.C., Rijken, M., Schellevis, F.G. Health care utilization of patients with multiple chronic diseases in the Netherlands: differences and underlying factors. European Journal of Internal Medicine: 2016, 35(11), 44-50

listed in a general practice. Recording in EHRs is most likely accurate since practices used these files for reimbursement claims with insurance companies.

A limitation might be incompleteness of the DHD database: in $201014 \%$ of the hospitals did not provide data [24]. This might have led to an underestimation of the actual number of admitted persons as well as the actual number of admissions per person, but there is no reason to expect that this underestimation is more pronounced in specific patient groups (i.e. within multimorbid patients or patients with a single chronic disease, or within specific clusters of multimorbid patients) thereby affecting the study outcomes.

Possible mistakes in ICPC recording (i.e. typing errors or incorrect coding) could have been made, but it is unlikely that coding errors would differ systematically between the different clusters of multimorbid patients, or between multimorbid patients and patients with a single chronic disease.

\section{CONCLUSION}

Health care utilization among multimorbid patients is higher compared to patients with a single chronic disease, but a large proportion of the people with multimorbidity (about $60 \%$ ) has only a slightly higher health care utilization. Compared to multimorbid patients with polypharmacy, multimorbid patients without polypharmacy have a relatively low level of health care utilization suggesting that these people - with the right support - are fairly able to provide in their own care and manage their conditions. Heightened (or extensive, applying to almost $8 \%$ of the patients) health care utilization among patients with multimorbidity is related to a higher number of chronic diseases as well as to specific types of diseases, such as heart failure, COPD, and diabetes mellitus. Patient characteristics such as age, household size, and income also impact on healthcare use among multimorbid patients. This should be taken into account, when identifying target groups for integrated care programmes.

It would be interesting to study patients with characteristics that seem to be connected with higher health care use before they develop multimorbidity or polypharmacy, to develop strategies to affect the clinical evolution with primary or secondary prevention policies. Finally, it would be important to collect prospective data for the three subgroups on outcomes, such as mortality. Results could be used to plan effective actions to improve patients' quality of life as well as health and economical resource utilization.

\section{Acknowledgments}

This research arises from the Joint Action on Chronic Diseases and Promoting Healthy Aging Across the Life Cycle (JA-CHRODIS) which has received funding from the European Union, in the framework of the Health Programme 2008-2013 (GA 201322 01). NIVEL has also received funding from the Netherlands Ministry of Health, Welfare and Sports to contribute to this joint action (GA 322095). 
Hopman, P., Heins, M.J., Korevaar, J.C., Rijken, M., Schellevis, F.G. Health care utilization of patients with multiple chronic diseases in the Netherlands: differences and underlying factors. European Journal of Internal Medicine: 2016, 35(11), 44-50

\section{Conflict of interest}

The authors have no competing interests to report.

Appendix A. ICPC codes of the 29 examined chronic diseases

\begin{tabular}{|c|c|c|}
\hline & Chronic disease & ICPC-code(s) \\
\hline 1 & Anxiety disorder & P74 \\
\hline 2 & Asthma & R96 \\
\hline 3 & Cancer & $\begin{array}{l}\text { A79, B72-B74, D75-D77, L71, N74, R84, R85, S77, } \\
\text { T71, U75-U77, W72, X75-X77, Y77, Y78 }\end{array}$ \\
\hline 4 & Cardiac dysrhythmia & K78-K80 \\
\hline 5 & Chronic alcohol abuse & P15 \\
\hline 6 & Chronic back or neck disorder & L83, L84, L86 \\
\hline 7 & $\begin{array}{l}\text { Congenital cardiovascular } \\
\text { anomaly }\end{array}$ & K73 \\
\hline 8 & COPD & R91, R95 \\
\hline 9 & Coronary artery disease & K74-K76 \\
\hline 10 & $\begin{array}{l}\text { Dementia (incl. Alzheimer's } \\
\text { disease) }\end{array}$ & P70 \\
\hline 11 & Depression (and psychosis) & $\mathrm{P73}, \mathrm{P} 76$ \\
\hline 12 & Diabetes mellitus & T90 \\
\hline 13 & Epilepsy & $\mathrm{N} 88$ \\
\hline 14 & Hearing disorder & H84-H86 \\
\hline 15 & Heart failure & K77 \\
\hline 16 & Heart valve disorder & K83 \\
\hline 17 & HIV/AIDS & B90 \\
\hline 18 & Hypertension & K86, K87 \\
\hline 19 & Mental retardation & P85 \\
\hline 20 & Migraine & N89 \\
\hline 21 & $\begin{array}{l}\text { Neuraesthenia/surmenage/burn- } \\
\text { out }\end{array}$ & P78 \\
\hline 22 & Osteoarthritis & L89-L91 \\
\hline 23 & Osteoporosis & L95 \\
\hline 24 & Parkinson's disease & N97 \\
\hline 25 & Personality disorder & P80 \\
\hline 26 & Rheumatoid arthritis & L88 \\
\hline 27 & Schizophrenia & P72 \\
\hline 28 & Stroke & K90 \\
\hline 29 & Visual disorder & F83, F84, F92-F94 \\
\hline
\end{tabular}


Hopman, P., Heins, M.J., Korevaar, J.C., Rijken, M., Schellevis, F.G. Health care utilization of patients with multiple chronic diseases in the Netherlands: differences and underlying factors. European Journal of Internal Medicine: 2016, 35(11), 44-50

APPENDIX B. PREVALENCE OF 29 CHRONIC CONDITIONS AMONG A SAMPLE OF PEOPLE WITH MULTIMORBIDITY AND AMONG A SAMPLE OF PEOPLE WITH ONE CHRONIC CONDITION (2010)

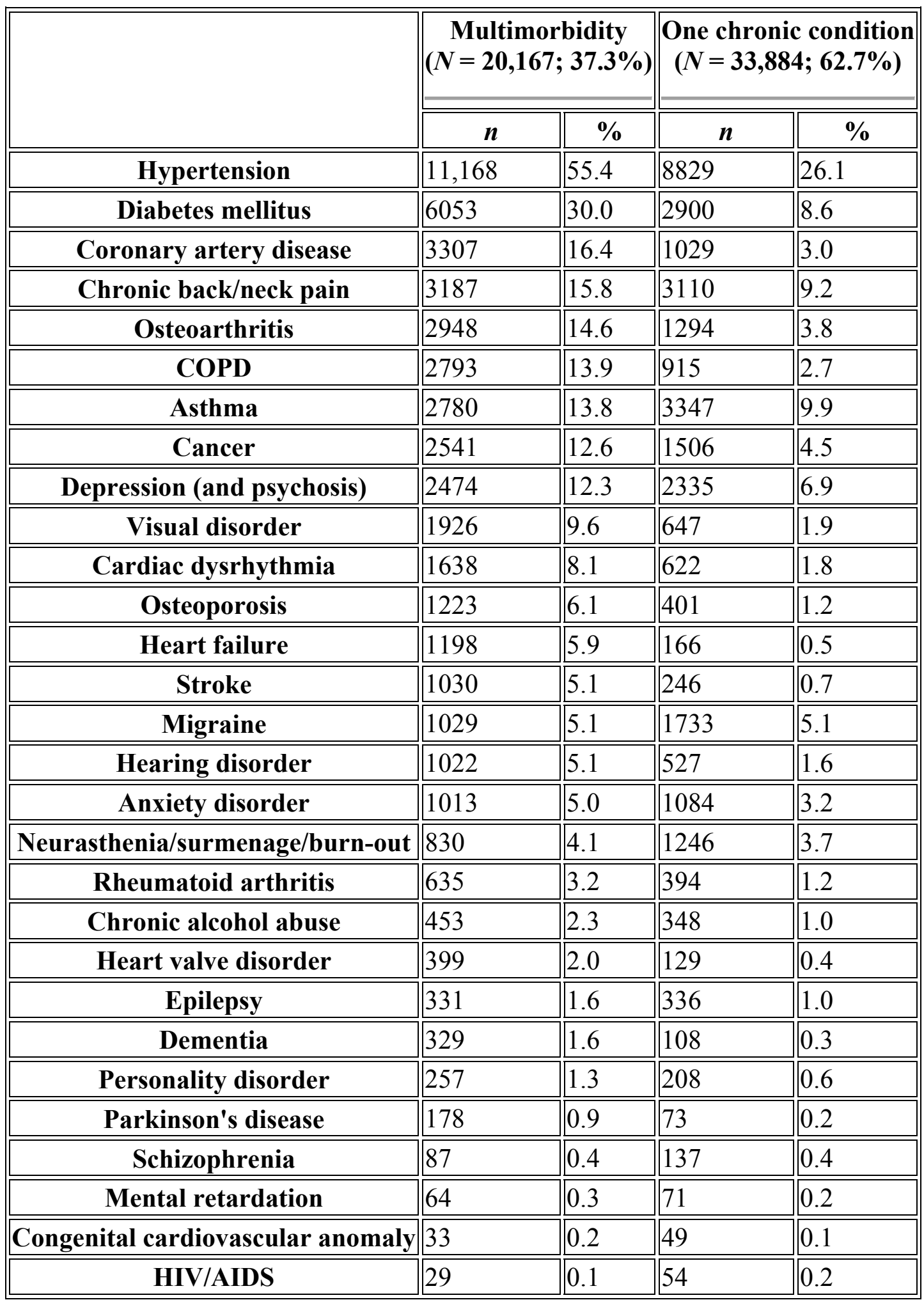


Hopman, P., Heins, M.J., Korevaar, J.C., Rijken, M., Schellevis, F.G. Health care utilization of patients with multiple chronic diseases in the Netherlands: differences and underlying factors. European Journal of Internal Medicine: 2016, 35(11), 44-50

APPENDIX C. THE DISTRIBUTION OVER THE THREE CLUSTERS OF PATIENTS WITH A CERTAIN CHRONIC DISEASE; GREEN IMPLIES FEWER PATIENTS (THAN AVERAGE) IN THAT CLUSTER, AND RED IMPLIES MORE PATIENTS (THAN AVERAGE) IN THAT CLUSTER

\begin{tabular}{llllc}
\hline & $\begin{array}{l}\text { Cluster } 1 \\
(n=9385 ; 56.9 \%)\end{array}$ & $\begin{array}{l}\text { Cluster } 2 \\
(n=5847 ; 35.5 \%)\end{array}$ & $\begin{array}{l}\text { Cluster } 3 \\
(n=1250 ; 7.6 \%)\end{array}$ & $p$ \\
\hline Heart failure & $33.2 \%$ & $47.5 \%$ & $19.2 \%$ & $<0.0001$ \\
\hline COPD & $44.2 \%$ & $42.7 \%$ & $13.2 \%$ & $<0.0001$ \\
\hline Osteoporosis & $47.3 \%$ & $42.4 \%$ & $10.4 \%$ & $<0.0001$ \\
\hline Cardiac dysrhythmia & $48.1 \%$ & $41.6 \%$ & $10.4 \%$ & $<0.0001$ \\
\hline Stroke & $48.6 \%$ & $41.0 \%$ & $10.4 \%$ & $<0.0001$ \\
\hline CAD & $48.7 \%$ & $41.8 \%$ & $9.5 \%$ & $<0.0001$ \\
\hline Diabetes mellitus & $49.6 \%$ & $39.4 \%$ & $11.0 \%$ & $<0.0001$ \\
\hline Osteoarthritis & $52.8 \%$ & $38.4 \%$ & $8.9 \%$ & $<0.0001$ \\
\hline Visual disorder & $53.1 \%$ & $37.4 \%$ & $9.5 \%$ & $<0.0001$ \\
\hline Hypertension & $55.0 \%$ & $37.5 \%$ & $7.5 \%$ & $<0.0001$ \\
\hline Cancer & $55.7 \%$ & $35.3 \%$ & $8.9 \%$ & 0.049 \\
\hline Asthma & $56.3 \%$ & $36.3 \%$ & $7.4 \%$ & 0.64 \\
\hline Depression & $56.4 \%$ & $34.9 \%$ & $8.7 \%$ & 0.14 \\
\hline Hearing disorder & $58.5 \%$ & $35.8 \%$ & $5.7 \%$ & 0.09 \\
\hline Chronic back/neck pain & $58.7 \%$ & $34.3 \%$ & $7.0 \%$ & 0.11 \\
\hline Anxiety disorder & $58.7 \%$ & $29.9 \%$ & $11.4 \%$ & $<0.0001$ \\
\hline Migraine & $64.4 \%$ & $30.7 \%$ & $4.9 \%$ & $<0.0001$ \\
\hline
\end{tabular}

\section{REFERENCES}

[1] van Oostrom SH, Gijsen R, Stirbu I, Korevaar JC, Schellevis FG, Picavet HSJ, et al. Rise in the prevalence of chronic diseases and multimorbidity from 2001 to 2011 in the Dutch population; 2014[Manuscript submitted for publication].

[2] Eurostat.

http://epp.eurostat.ec.europa.eu/portal/page/portal/health/public_health/data_public_health/ database. [Table people having a long-standing illness or health problem, by sex, age and income quintile, year] 2010.

[3] Busse R, Blümel M, Scheller-Kreinsen D, Zentner A. Tackling chronic disease in Europe. Strategies, interventions and challenges. Observatory studies series no. 20. World Health Organization, on behalf of the European Observatory on Health Systems and Policies series; 2010.

[4] Boyd C, Fortin M. Future of multimorbidity research: how should understanding of multimorbidity inform health system design? Public Health Rev 2010;32:451-74. 
Hopman, P., Heins, M.J., Korevaar, J.C., Rijken, M., Schellevis, F.G. Health care utilization of patients with multiple chronic diseases in the Netherlands: differences and underlying factors. European Journal of Internal Medicine: 2016, 35(11), 44-50

[5] Uijen AA, van de Lisdonk EH. Multimorbidity in primary care: prevalence and trend over the last 20 years. Eur J Gen Pract 2008;14(1):28-32. http://dx.doi.org/10.1080/13814780802436093.

[6] Bower P, Macdonald W, Harkness E, Gask L, Kendrick T, Valderas JM, et al. Multimorbidity, service organization and clinical decision making in primary care: a qualitative study. Fam Pract 2011;28(5):579-87. http://dx.doi.org/10.1093/fampra/cmr018.

[7] Smith SM, Soubhi H, Fortin M, Hudon C, O'Dowd T. Managing patients with multimorbidity: systematic review of interventions in primary care and community settings. Cochrane Database Syst Rev 2012;2012(4). http://dx.doi.org/10.1002/14651858.CD006560.pub2 .

[8] Rijken M, Struckmann V, Dyakova M, Melchiorre MG, Rissanen S, van Ginneken E.ICARE4EU: improving care for people with multiple chronic conditions in Europe. Eurohealth 2013;19(3):29-31.

[9] Marengoni A, Angleman S, Melis R, Mangialasche F, Karp A, Garmen A, et al. Aging with multimorbidity: a systematic review of the literature. Aging Res Rev 2011;10: 430-9. http://dx.doi.org/10.1016/j.arr2011.03.003.

[10] Vogeli C, Shields AE, Lee TA, Gibson TB,MarderWD, Weiss KB, et al.Multiple chronic conditions: prevalence, health consequences, and implications for quality, caremanagement, and costs. J Gen InternMed 2007;22(Suppl. 3):391-5. http://dx.doi.org/101007/s11606-007-0322-1.

[11] Kadam UT, Croft, P. R. North Staffordshire GP Consortium group. Clinical multimorbidity and physical function in older adults: a record and health status linkage study in general practice. Fam Pract 2007;24(5):412-9. http://dx.doi.org/10.1093/fampra/cmm049.

[12] Rijken M, Kerkhof Mv, Dekker J, Schellevis FG. Comorbidity of chronic diseases: effects of disease pairs on physical and mental functioning. Qual Life Res 2005;14(1):45-55. http://dx.doi.org/10.1007/s11136-004-0616-2.

[13] Fortin M, Bravo G, Hudon C, Lapointe L, Almirall J, Dubois MF, et al. Relationship between multimorbidity and health-related quality of life of patients in primary care. Qual Life Res 2006;15:83-91. http://dx.doi.org/10.1007/s11136-005-8661-z.

[14] Hopman P, Schellevis FG, Rijken M. Health-related needs of people with multiple chronic diseases: differences and underlying factors. Qual Life Res 2016;25(3): 651-60. http://dx.doi.org/10.1007/s11136-015-1102-8.

[15] Fortin M, Bravo G, Hudon C, Lapointe L, Dubois MF, Almirall J. Psychological distress andmultimorbidity in primary care. Ann FamMed 2006;4(5):417-22. http://dx.doiorg/10.1370/afm.528.

[16] Menotti A, Mulder I, Nissinen A, Giampaoli S, Feskens EJ, Kromhout D. Prevalence of morbidity and multimorbidity in elderly male populations and their impact on 10-year allcause mortality: the FINE study (Finland, Italy, Netherlands, elderly). J Clin Epidemiol 2001;54:680-6. http://dx.doi.org/10.1016/S0895-4356(00)00368-1.

[17] de Bruin SR, Heijink R, Lemmens L, Struijs JN, Baan CA. Impact of disease management programs on healthcare expenditures for patients with diabetes, depression, heart failure or chronic obstructive pulmonary disease: a systematic review of the literature. Health Policy 2011;101:105-21. http://dx.doi.org/10.1016/j.healthpol.2011.03.006.

[18] Boult C, Green AF, Boult LB, Pacala JT, Snyder C, Leff B. Successful models of comprehensive care for older adults with chronic conditions: evidence for the institute of medicine's "retooling for an aging America" report. J Am Geriatr Soc 2009;57: 2328-37. http://dx.doi.org/10.1111/j.1532-5415.2009.02571.x.

[19] Hopman EPC, de Bruin SR, Forjaz J, Rodriguez Blazquez C, Tonnara G, Lemmens LC, et al. Effectiveness of comprehensive care programs for patients with multiple chronic conditions or frailty: a systematic literature review. Health Policy 2016. http://dx.doi.org/10.1016/j.healthpol.2016.04.002 [Advance online publication].

[20] Sinnige J, Korevaar JC, Westert GP, Spreeuwenberg P, Schellevis FG, Braspenning JC. Multimorbidity patterns in a primary care population aged 55 years and over. Fam Pract 2015;32(5):505-13. http://dx.doi.org/10.1093/fampra/cmv037.

[21] http://www.nivel.nl/en/dossier/nivel-primary-care-database. [22] Verheij RA. Over NIVEL zorgregistraties: geschiedenis en achtergrond. Uit: NIVEL zorgregistraties eerste lijn. www.nivel.nl/node/3464; 2013. [Last update March 10, 2014. Accessed March 20, 2014]. 
Hopman, P., Heins, M.J., Korevaar, J.C., Rijken, M., Schellevis, F.G. Health care utilization of patients with multiple chronic diseases in the Netherlands: differences and underlying factors. European Journal of Internal Medicine: 2016, 35(11), 44-50

[23] Lamberts $\mathrm{H}$, Wood M. The birth of the international classification of primary care (ICPC). Serendipity at the border of Lac Léman. Fam Pract 2002;19:433-5. http://dx.doi.org/10.1093/fampra/19.5.433.

[24] Statistics Netherlands/Centraal Bureau voor de Statistiek, Centrum voor Beleidsstatistiek. Documentatierapport Landelijke Medische Registratie (LMR) $2011 \mathrm{~V} 1$. 2013 [Retrieved from] http://www.cbs.nl/NR/rdonlyres/AA18B546-CA6E-40C6-8B171BB976F1C4E5/0/Imrmicrodata.pdf. [on March 31, 2014].

[25] Statistics Netherlands/Centraal Bureau voor de Statistiek, Centrum voor Beleidsstatistiek. Documentatierapport Woononderzoek Nederland (WoON) 2012. 2013 [Retrieved from] http://www.cbs.nl/NR/rdonlyres/9EAD3408-D873-465EA0F538C810832FBA/0/woonmicrodata.pdf. [on May 13, 2014].

[26] van Oostrom SH, Picavet HS, van Gelder BM, Lemmens LC, Hoeymans N, Verheij RA, et al.Multimorbidity and comorbidity in the Dutch population-data from general practices. BMC Public Health 2012;12:715. http://dx.doi.org/10.1186/1471-2458-12-715.

[27] Lawless JF. Negative binomial and mixed Poisson regression. Can J Stat 1987;15(3): 209-25.

[28] Stata.com. Cluster analysis. 2014 [Retrieved from] http://www.stata.com/features/lusteranalysis/. [on December 12, 2014].

[29] van Oostrom SH, Picavet HSJ, de Bruin SR, Stirbu I, Korevaar JC, Schellevis FG, et al. Multimorbidity of chronic diseases and health care utilization in general practice. BMC Fam Pract 2014;15:61. http://dx.doi.org/10.1186/1471-2296-15-61.

[30] Bähler C, Huber CA, Brüngger B, Reich O. Multimorbidity, health care utilization and costs in an elderly community-dwelling population: a claims data based observational study. BMC Health Serv Res 2015;15(23).

[31] Lane NE,Maxwell CJ, Gruneir A, Bronskill SE,WodchisWP. Absence of a socioeconomic gradient in older adults' survival withmultiple chronic conditions. EBioMedicine 2015; 2(12):2094-100. http://dx.doi.org/10.1016/j.ebiom.2015.11.018.

[32] Alonso-Morá E, Nuño-Solinis R, Onder G, Tonnara G. Multimorbidity in risk stratification tools to predict negative outcomes in adult population. Eur J Intern Med 2015; 26:182-9. http://dx.doi.org/10.1016/j.ejim.2015.02.010.

[33] Eckardt M, Brettschneider C, van den Bussche H, König HH. MultiCare Study Group. Analysis of health care costs in elderly patients with multiple chronic conditions using a finite mixture of generalized linear models. Health Econ 2016. http://dx.doi.org/10.1002/hec.

[34] Zulman DM, Pal Chee C, Wagner TH, Yoon J, Cohen DM, Holmes TH, et al. Multimorbidity and healthcare utilisation among high-cost patients in the US veterans affairs health care system. BMJ Open 2015;5. http://dx.doi.org/10.1136/bmjopen-2015$\underline{007771 .}$. 
Hopman, P., Heins, M.J., Korevaar, J.C., Rijken, M., Schellevis, F.G. Health care utilization of patients with multiple chronic diseases in the Netherlands: differences and underlying factors. European Journal of Internal Medicine: 2016, 35(11), 44-50

\section{TABLES}

Table 1. Health care utilization in the year 2010 of people with multimorbidity versus one chronic condition $(N=54,051)$.

\begin{tabular}{|c|c|c|c|c|c|}
\hline & \multicolumn{2}{|c|}{$\begin{array}{c}\text { Multimorbidity } \\
\text { (n=20,167; } \\
37.3 \%)\end{array}$} & \multicolumn{2}{|c|}{$\begin{array}{c}\text { One chronic } \\
\text { condition } \\
(n=33,884 \\
62.7 \%)\end{array}$} & \multirow[t]{2}{*}{$(L R) \chi^{2}, p$} \\
\hline & $n$ & $\%$ & $n$ & $\%$ & \\
\hline \multicolumn{6}{|l|}{ GP contact } \\
\hline$\geq 1$ GP contact & 18,952 & 93.98 & 29,163 & 86.17 & $\begin{array}{l}\chi 2(1)=791.90, \\
p<0.0001\end{array}$ \\
\hline $\begin{array}{c}\text { Number of GP contacts } \\
(\text { M, SD) }\end{array}$ & $\left(\begin{array}{l}8.54 \\
(7.90)\end{array}\right.$ & & $\left(\begin{array}{l}5.13 \\
(5.36)\end{array}\right.$ & & $\begin{array}{l}\mathrm{LR} \chi 2 \\
(1)=3641.68 \\
\mathrm{p}<0.0001\end{array}$ \\
\hline \multicolumn{6}{|l|}{ Prescribed medication } \\
\hline $\begin{array}{c}\text { Number of prescribed } \\
\text { different medications } \\
(\mathrm{M}, \mathrm{SD}) \mathrm{a}\end{array}$ & $\begin{array}{l}7.07 \\
(4.32)\end{array}$ & & $\left(\begin{array}{l}3.90 \\
(3.26)\end{array}\right.$ & & $\begin{array}{l}\mathrm{LR} \chi 2 \\
(1)=7848.62 \\
p<0.0001\end{array}$ \\
\hline Polypharmacyb & 5031 & 24.95 & 2153 & 6.36 & $\begin{array}{l}\chi^{2}(1)=3800 \\
p<0.0001\end{array}$ \\
\hline \multicolumn{6}{|c|}{ Hospital admission $(\mathrm{n}=42,776) \mathrm{c}$} \\
\hline$\geq 1$ day care admission & 2346 & 14.23 & 2308 & 8.78 & $\begin{array}{l}\chi^{2}(1)=311.04, \\
p<0.0001\end{array}$ \\
\hline$\geq 1$ inpatient admission & 2608 & 15.82 & 2300 & 8.75 & $\begin{array}{l}\chi^{2}(1)=499.43, \\
p<0.0001\end{array}$ \\
\hline
\end{tabular}

a) Different types, on ATC3-level.

b) $\geq 10$ prescriptions (different types, on ATC3-level).

c) Calculation by NIVEL based on micro data files on Dutch Hospital Data, made available by Statistics Netherlands. 
Hopman, P., Heins, M.J., Korevaar, J.C., Rijken, M., Schellevis, F.G. Health care utilization of patients with multiple chronic diseases in the Netherlands: differences and underlying factors. European Journal of Internal Medicine: 2016, 35(11), 44-50

Table 2. Description of multimorbidity clusters according to health care utilization in the year $2010(N=16,482)$.

\begin{tabular}{|c|c|c|c|c|c|c|c|}
\hline & \multicolumn{2}{|c|}{$\begin{array}{c}\text { Cluster } 1 \\
(n=9385 \\
56.9 \%)\end{array}$} & \multicolumn{2}{|c|}{$\begin{array}{c}\text { Cluster } 2 \\
(n=5847 \\
35.5 \%)\end{array}$} & \multicolumn{2}{|c|}{\begin{tabular}{|c|} 
Cluster 3 \\
$(n=1250$ \\
$7,6 \%)$
\end{tabular}} & \multirow[t]{2}{*}{$(L R) \chi^{2}, p$} \\
\hline & $n$ & $\%$ & $N$ & $\%$ & $n$ & $\%$ & \\
\hline \multicolumn{8}{|l|}{ GP contact } \\
\hline$\geq 1$ GP contacta & 8435 & 89.9 & 5847 & 100 & 1250 & 100 & $\begin{array}{l}\chi^{2}(2)=762.34 \\
p<0.0001\end{array}$ \\
\hline $\begin{array}{l}\text { Number of GP } \\
\text { contacts }(M, S D)\end{array}$ & \multicolumn{2}{|l|}{$\begin{array}{l}3.8 \\
(2.4)\end{array}$} & \multicolumn{2}{|l|}{$\mid \begin{array}{l}11.8 \\
(3.5)\end{array}$} & \multicolumn{2}{|l|}{$\begin{array}{l}28.0 \\
(9.6)\end{array}$} & $\begin{array}{l}\text { LR } \chi 2 \\
(2)=19,959.85, \\
p<0.0001\end{array}$ \\
\hline \multicolumn{8}{|l|}{ Prescribed medication } \\
\hline \begin{tabular}{|c|} 
Number of \\
prescribed different \\
medications (M, \\
SD)b
\end{tabular} & \multicolumn{2}{|l|}{$\begin{array}{l}4.8 \\
(2.7)\end{array}$} & \multicolumn{2}{|l|}{$\mid \begin{array}{l}9.3 \\
(3.6)\end{array}$} & \multicolumn{2}{|l|}{$\begin{array}{l}13.3 \\
(4.7)\end{array}$} & $\begin{array}{l}\mathrm{LR} \chi 2 \\
(2)=8280.67 \\
p<0.0001\end{array}$ \\
\hline \begin{tabular}{|c|} 
Polypharmacy (M, \\
SD)c
\end{tabular} & 513 & 5.5 & 2573 & 44.0 & 978 & 78.2 & $\begin{array}{l}\chi 2(2)=5000 \\
p<0.0001\end{array}$ \\
\hline \multicolumn{8}{|l|}{ Hospital admissiond } \\
\hline $\begin{array}{l}\geq 1 \text { day care } \\
\text { admission }\end{array}$ & 934 & 10.0 & 1093 & 18.7 & 319 & 25.5 & $\begin{array}{l}\chi 2(2)=366.62, \\
p<0.0001\end{array}$ \\
\hline $\begin{array}{l}\geq 1 \text { inpatient } \\
\text { admission }\end{array}$ & 861 & 9.2 & 1272 & 21.8 & 475 & 38.0 & $\begin{array}{l}\chi 2(2)=927.49 \\
p<0.0001\end{array}$ \\
\hline
\end{tabular}

a) This variable was not used in the cluster analysis since it was directly derived from the variable 'Number of GP contacts' (which was included in the analysis).

b) Different types, on ATC3-level.

c) $\geq 10$ prescriptions (different types, on ATC3-level). This variable was not used in the cluster analysis since it was directly derived from the variable 'Number of prescribed different medications' (which was included in the analysis).

d) Calculation by NIVEL based on micro data files on Dutch Hospital Data, made available by Statistics Netherlands. 
Hopman, P., Heins, M.J., Korevaar, J.C., Rijken, M., Schellevis, F.G. Health care utilization of patients with multiple chronic diseases in the Netherlands: differences and underlying factors. European Journal of Internal Medicine: 2016, 35(11), 44-50

Table 3. Patient and illness-related characteristics (in the year 2010) of people within the multimorbidity clusters $(N=16,482)$.

\begin{tabular}{|c|c|c|c|c|c|c|c|}
\hline & \multicolumn{2}{|c|}{\begin{tabular}{|c} 
Cluster 1 \\
$(n=9385 ;$ \\
$56.9 \%)$
\end{tabular}} & \multicolumn{2}{|c|}{$\begin{array}{c}\text { Cluster } 2 \\
(n=5847 \\
35.5 \%)\end{array}$} & \multicolumn{2}{|c|}{$\begin{array}{c}\text { Cluster } 3 \\
(n=1250 ; \\
7,6 \%)\end{array}$} & \multirow[t]{2}{*}{$(L R) \chi^{2}, p$} \\
\hline & $n$ & $\%$ & $n$ & $\%$ & $n$ & $\%$ & \\
\hline \multicolumn{8}{|c|}{ Patient characteristics } \\
\hline \multicolumn{8}{|l|}{ Gender } \\
\hline - Male & 4336 & 46.2 & 2206 & 37.7 & 371 & 29.7 & \multirow{2}{*}{$\begin{array}{l}\chi 2(2)=189.73 \\
p<0.0001\end{array}$} \\
\hline - Female & 5049 & 53.8 & 3641 & 62.3 & 879 & 70.3 & \\
\hline Age (M, SD) & \multicolumn{2}{|l|}{$\begin{array}{l}63.1 \\
(14.0)\end{array}$} & \multicolumn{2}{|c|}{$\begin{array}{l}68.0 \\
(13.8)\end{array}$} & \multicolumn{2}{|c|}{\begin{tabular}{|l}
71.7 \\
$(14.2)$
\end{tabular}} & $\begin{array}{l}F(2, \\
16,479)=353.53, \text { adj } \\
R 2=0.04, p<0.0001\end{array}$ \\
\hline $\begin{array}{c}\text { Disposable } \\
\text { income }(€) \text { in the } \\
\text { year } 2010(M, \\
\text { SD)a }\end{array}$ & \multicolumn{2}{|c|}{\begin{tabular}{|l}
33,306 \\
$(21,212)$
\end{tabular}} & \multicolumn{2}{|c|}{$\begin{array}{l}28,930 \\
(16,887)\end{array}$} & \multicolumn{2}{|c|}{\begin{tabular}{||l}
25,030 \\
$(12,921)$
\end{tabular}} & $\begin{array}{l}F(2, \\
16,478)=161.10, \text { adj } \\
R 2=0.02, \\
p<0.0001 b\end{array}$ \\
\hline $\begin{array}{l}\text { Household size } \\
\text { (M, SD)a/c }\end{array}$ & \multicolumn{2}{|l|}{$\left(\begin{array}{l}2.1 \\
(1.0)\end{array}\right.$} & \multicolumn{2}{|l|}{$\begin{array}{l}1.9 \\
(1.0)\end{array}$} & \multicolumn{2}{|l|}{$\mid \begin{array}{l}1.7 \\
(0.8)\end{array}$} & $\begin{array}{l}\mathrm{F}(2, \\
16,478)=126.21, \text { adj } \\
\mathrm{R} 2=0.02, \mathrm{p}<0.0001\end{array}$ \\
\hline \multicolumn{8}{|c|}{ Illness-related characteristics } \\
\hline $\begin{array}{c}\text { Number of } \\
\text { chronic diseases } \\
(M, S D) \\
\end{array}$ & \multicolumn{2}{|l|}{\begin{tabular}{|l}
2.4 \\
$(0.7)$
\end{tabular}} & \multicolumn{2}{|l|}{$\begin{array}{l}2.7 \\
(1.0)\end{array}$} & \multicolumn{2}{|l|}{$\mid \begin{array}{l}3.1 \\
(1.2)\end{array}$} & $\begin{array}{l}\operatorname{LR} \chi 2(2)=311.28 \\
p<0.0001 d\end{array}$ \\
\hline \multicolumn{8}{|l|}{ Chronic diseasee } \\
\hline - Hypertension & $\mid 5144$ & 54.8 & $\mid 3511$ & |60.1 & ||699 & $\mid 55.9$ & $\begin{array}{l}\chi 2(2)=40.64 \\
p<0.0001\end{array}$ \\
\hline $\begin{array}{c}\text { - Diabetes } \\
\text { mellitus }\end{array}$ & 2457 & 26.2 & $\mid 1954$ & | 33.4 & $\mid 544$ & 43.5 & $\begin{array}{l}\chi^{2}(2)=206.28, \\
p<0.0001\end{array}$ \\
\hline \begin{tabular}{|c|}
$-\begin{array}{c}\text { Coronary artery } \\
\text { disease }\end{array}$ \\
\end{tabular} & 1333 & 14.2 & 1146 & || 19.6 & $\mid 260$ & 20.8 & $\begin{array}{l}\chi^{2}(2)=92.78 \\
p<0.0001\end{array}$ \\
\hline $\begin{array}{c}\text { - Chronic } \\
\text { back/neck pain } \\
\end{array}$ & 1532 & 16.3 & 895 & 15.3 & 182 & 14.6 & $\chi 2(2)=4.43, p=0.11$ \\
\hline - Osteoarthritis & 1306 & 13.9 & 949 & 16.2 & $\mid 219$ & $\mid 17.5$ & $\begin{array}{l}\chi^{2}(2)=21.81 \\
p<0.0001\end{array}$ \\
\hline - COPD & 1004 & 10.7 & 970 & 16.6 & ||299 & 23.9 & $\begin{array}{l}\chi^{2}(2)=221.91 \\
p<0.0001\end{array}$ \\
\hline - Asthma & 1263 & 13.5 & 815 & 13.9 & 165 & 13.2 & $\chi^{2}(2)=0.90, p=0.64$ \\
\hline - Cancer & 1131 & 12.1 & 717 & 12.3 & 181 & 14.5 & $\chi 2(2)=6.05$ \\
\hline
\end{tabular}


Hopman, P., Heins, M.J., Korevaar, J.C., Rijken, M., Schellevis, F.G. Health care utilization of patients with multiple chronic diseases in the Netherlands: differences and underlying factors. European Journal of Internal Medicine: 2016, 35(11), 44-50

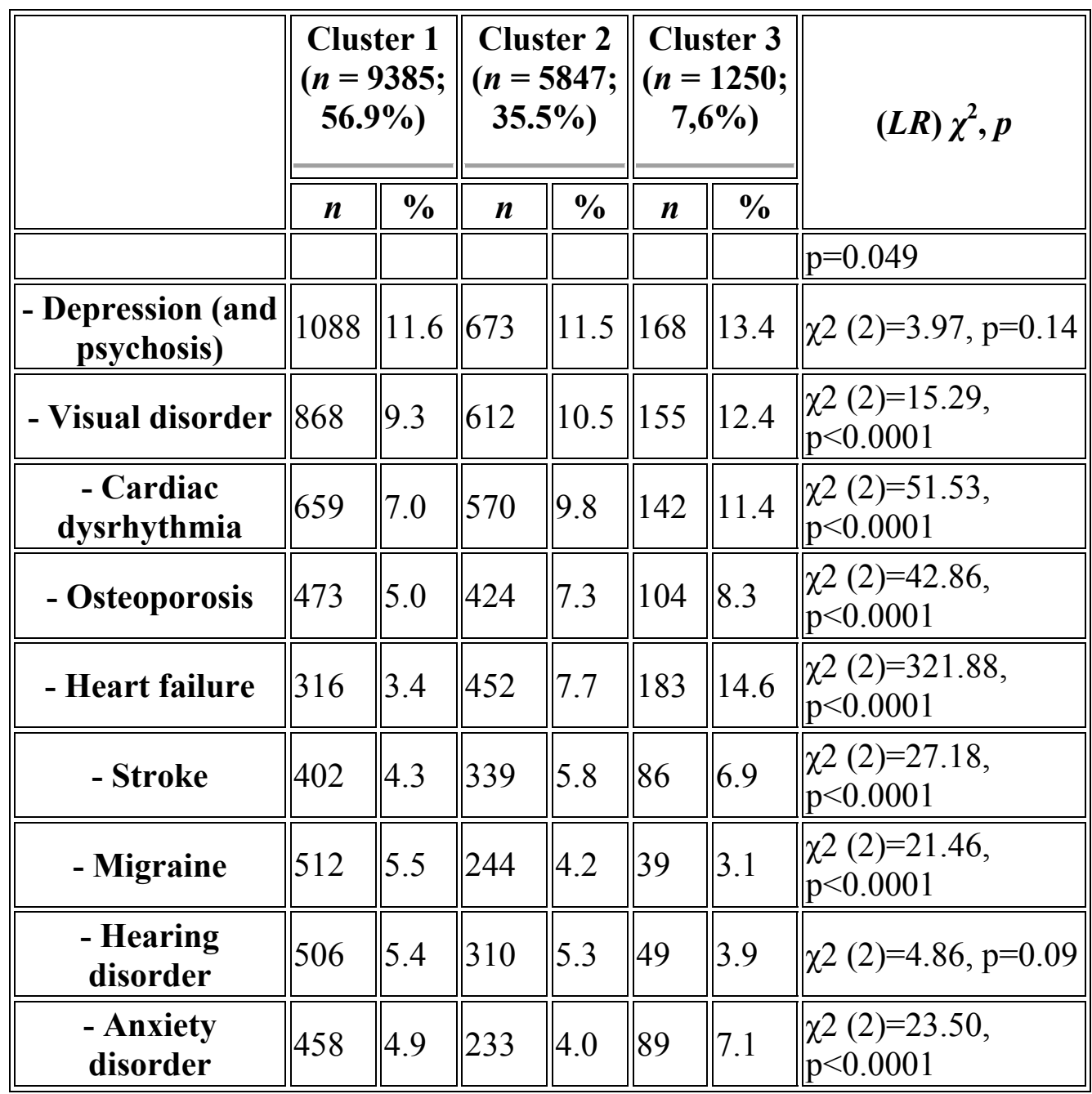

a) Calculation by NIVEL based on micro data files on Integral Household Incomes, made available by Statistics Netherlands.

b) The difference in average disposable income between clusters remains when corrected for age and gender.

c) Including the patient him/herself.

d) One patient with nine different comorbidities was deleted, as the model would not converge with this observation.

e) Diseases that were present in less than $5.0 \%$ of the sample with multimorbidity are not displayed here. 